\title{
Pemodelan Produksi Biogas pada Reaktor Tipe Batch dengan Menggunakan Metode Hamming Predictor-Corrector
}

\author{
Ali Assegaf ${ }^{1}$, Rian Febrian Umbara ${ }^{2}$, Isman Kurniawan ${ }^{3}$ \\ Prodi Informatika, Fakultas Informatika, Universitas Telkom \\ Jl. Telekomunikasi No. 1 Terusan Buah Batu, Bandung, Indonesia \\ 1 aliassegaf14@gmail.com \\ 2 rianum123@gmail.com \\ 3 isman.krn@gmail.com
}

\begin{abstract}
This research aimed to implement a model that is feasible to the condition of biogas production by using a batch reactor. The concentration of produced biogas is predicted by using a model that is commonly used in the anaerobic digestion process, i.e. Anaerobic Digestion Model No. 1 (ADM1). ADM1 model is transformed into a differential equation system and solved by using the Hamming predictor-corrector method. This method is a multi-step linear method that expresses a value in a point as a linear combination of previous points. The simulation of biogas production is performed for 120 hours by defining the initial concentration of the substrate as $500 \mathrm{mgCOD} / \mathrm{L}$. From the simulation, we found that the maximum concentration of methane that is obtained at the end of the simulation is $417,48 \mathrm{mgCOD} / \mathrm{L}$. Also, the microorganism that consumes glucose grow faster than others. The results also show that the initial concentration of glucose and microorganism affect the concentration of produced methane.
\end{abstract}

Keywords: ADM1, batch reactor, Hamming predictor-corrector method.

\begin{abstract}
Abstrak
Penelitian ini bertujuan untuk menerapkan model yang diharapkan sesuai dengan proses produksi biogas pada reaktor tipe batch. Jumlah biogas yang dihasilkan dari proses produksi tersebut diprediksi dengan menggunakan model yang sudah umum digunakan pada proses pencernaan anaerobik yaitu Anaerobic Digestion Model No 1 (ADM1). Model ADM1 ditransformasikan ke dalam bentuk sistem persamaan diferensial dan diselesaikan dengan metode Hamming predictor-corrector. Metode ini merupakan sebuah metode linear multilangkah yang mengekspresikan nilai pada suatu titik sebagai kombinasi linear dari titiktitik sebelumnya. Simulasi produksi biogas dilakukan selama 120 jam dengan mendefinisikan konsentrasi substrat awal $500 \mathrm{mgCOD} / \mathrm{L}$. Berdasarkan hasil simulasi, diketahui bahwa konsentrasi maksimal metana yang didapat di akhir simulasi adalah 417,48 mgCOD/L. Selain itu, pertumbuhan mikroorganisme yang mencerna glukosa lebih cepat dibandingkan pertumbuhan mikroorganisme yang lain. Hasil simulasi juga menunjukkan bahwa konsentrasi awal glukosa dan mikroorganisme sangat berpengaruh terhadap konsentrasi metana yang dihasilkan.
\end{abstract}

Kata Kunci: ADM1, reaktor tipe batch, metode Hamming predictor-corrector. 
Ali Assegaf. et.al.

Pemodelan Produksi Biogas...

\section{Pendahuluan}

$\mathbf{P}$

ERMASALAHAN di bidang energi akan menjadi topik yang akan selalu menarik untuk dikaji dan diteliti. [1], [2] Hal ini disebabkan oleh peningkatan terhadap kebutuhan energi dunia dikarenakan terus bertumbuhnya populasi penduduk dunia. [3] Selain itu, semakin menipisnya sumber cadangan minyak dunia menambah permasalahan energi yang juga memerlukan solusi. [4] Oleh karena itu, kebutuhan akan sumber energi alternatif sudah menjadi suatu keniscayaan untuk kondisi saat ini. Dewasa ini, berbagai sumber energi alternatif telah dikembangkan dan disiapkan untuk mengganti sumber energi utama, yang salah satunya adalah biogas. [4], [5]

Efektivitas produksi biogas diketahui sangat tergantung pada banyak faktor, di antaranya desain reaktor, jenis substrat awal, mikroba, dll. [6], [7] Oleh karena itu, proses optimasi produksi biogas menjadi sangat sulit dan mahal dikarenakan kompleksitas dan keterkaitan dari faktor-faktor tersebut. Maka dari itu, aplikasi komputasi untuk memodelkan produksi biogas sangat diperlukan agar proses optimasi lebih efisien. [8] Proses produksi biogas itu sendiri merupakan proses pencernaan anaerobik yang melibatkan serangkaian proses biokimia dan fisiko-kimia yang sangat kompleks. [6], [7] Untuk mengaproksimasi proses tersebut, diperlukan suatu model yang dapat mengekspresikan keterkaitan dari proses-proses tersebut. Model yang umum digunakan untuk mengaproksimasi suatu proses pencernaan anaerobik adalah Anaerobic Digestion Model No 1 (ADM1). Model ini pertama kali dikembangkan oleh International Water Asosiation (IWA) pada tahun 2002 dan merupakan model pertama yang dapat mendekati proses produksi biogas dengan cukup akurat. [6], [7] Implementasi ADM1 pada produksi biogas cukup efisien dalam mensimulasikan proses pencernaan anaerobik pada pengolahan limbah organik.

Biogas itu sendiri dapat dihasilkan dari berbagai macam jenis substrat, seperti gandum atau kotoran hewan. [9], [10] Proses biokimia terjadi dengan melibatkan berbagai jenis bakteri atau mikroorganisme dalam proses multi-level fermentasi anaerob. [6], [7] Target utama dari rangkaian proses ini adalah menghasilkan metana $\left(\mathrm{CH}_{4}\right)$ dengan jumlah yang diharapkan. Adapun konsentrasi metana yang dihasilkan tidak hanya dipengaruhi oleh jumlah dan komposisi substrat, tetapi juga dipengaruhi oleh faktor suhu, nilai $\mathrm{pH}$, dan beban digester. [8], [11]

Pada penelitian sebelumnya, untuk mengestimasi metana yang dihasilkan, ADM1 diselesaikan dengan menggunakan Livermore Solver dan metode Runge-Kutta-Gill, dan menghasilkan aproksimasi konsentrasi metana yang cukup akurat. [12], [13] Pada penelitian ini, penyelesaian formulasi pada ADM1 dilakukan dengan menggunakan metode Hamming predictor-corrector. Metode ini merupakan metode linear multilangkah yang mengekspresikan nilai pada suatu titik sebagai kombinasi linear dari titik-titik sebelumnya. [14]-[16] Salah satu keunggulan metode ini berkaitan dengan adanya tahap koreksi pada prediksi nilai awal sehingga dapat memperbaiki akurasi prediksi awal tersebut. Data eksperimen dari referensi rujukan [17] digunakan sebagai data pembanding untuk menentukan tingkat akurasi dari simulasi yang dilakukan.

\section{Metode Penelitian}

Pemodelan kinetika reaksi dari masing-masing spesi yang terlibat pada proses produksi biogas dilakukan dengan menggunakan Anaerobic Digestion Model No. 1 (ADM1). Implementasi model ini disesuaikan dengan kondisi eksperimen rujukan, [17] yakni konsentrasi glukosa sebagai substrat awal adalah $500 \mathrm{mgCOD} / \mathrm{L}$. Selain itu, pada studi ini, model ADM1 disesuaikan pula dengan jenis reaktor yang digunakan pada eksperimen rujukan yaitu reaktor tipe batch. Pada dasarnya, ADM1 mendefinisikan biogas yang dihasilkan sebagai kombinasi dari tiga komponen gas, yaitu metana, hidrogen dan karbondioksida. Akan tetapi, untuk menyederhanakan model yang dibangun, hanya komponen gas metana yang dipertimbangkan sebagai biogas yang dihasilkan dari proses produksi. Selain itu, metana diasumsikan terbentuk secara spontan tanpa melibatkan proses transfer gas.

Terkait dengan kinetika reaksi, hanya proses biokimia yang dipertimbangkan pada penelitian ini mengingat proses ini lebih dominan dibandingkan proses lain, yaitu proses fisiko-kimia. Formulasi kinetika reaksi dari masing-masing spesi serta keterkaitannya dengan masing-masing sub-proses ditampilkan pada Tabel I, dimana nomor proses dan spesi merujuk pada ADM1 [6]. Ekspresi dari persamaan laju yang tertera pada Tabel I ditunjukkan oleh Persamaan $1-10$. Nilai parameter yang digunakan pada penelitian ini 
TABLE I: Matriks proses biokimia

\begin{tabular}{|c|c|c|c|c|c|c|c|c|c|c|c|c|c|}
\hline \multicolumn{2}{|c|}{ Komponen } & 1 & 2 & 3 & 4 & 5 & 6 & 8 & 9 & 10 & 11 & 12 & \multirow[b]{2}{*}{ Laju } \\
\hline (j) & Proses & $\mathbf{S}_{\mathrm{su}}$ & $\mathbf{S}_{\mathrm{bu}}$ & $\mathrm{S}_{\text {pro }}$ & $\mathbf{S}_{\mathrm{ac}}$ & $S_{\mathrm{h} 2}$ & $\mathbf{S}_{\mathrm{ch} 4}$ & $\mathrm{X}_{\mathrm{su}}$ & $\mathbf{X}_{\mathrm{c} 4}$ & $\mathbf{X}_{\text {pro }}$ & $\mathbf{X}_{\mathrm{ac}}$ & $\mathbf{X}_{\mathrm{h} 2}$ & \\
\hline 5 & Penguraian glukosa & -1 & $\left(1-Y_{\mathrm{su}}\right) f_{\mathrm{bu}, \mathrm{su}}$ & $\left(1-Y_{\text {su }}\right) f_{\text {prosu }}$ & $\left(1-Y_{\mathrm{su}}\right) f_{\mathrm{ac}, \mathrm{su}}$ & $\left(1-Y_{\mathrm{su}}\right) f_{\mathrm{h} 2 \mathrm{su}}$ & & $Y_{\mathrm{su}}$ & & & & & $\rho_{5}$ \\
\hline 9 & Penguraian butirat & & -1 & & $\left(1-Y_{\mathrm{c} 4}\right) 0.8$ & $\left(1-Y_{\mathrm{c} 4}\right) 0.2$ & & & $Y_{\mathrm{c} 4}$ & & & & $\rho_{9}$ \\
\hline 10 & Penguraian propionat & & & -1 & $\left(1-Y_{\text {рго }}\right) 0.57$ & $\left(1-Y_{\text {рro }}\right) 0.43$ & & & & $Y_{\text {pro }}$ & & & $\rho_{10}$ \\
\hline 11 & Penguraian asetat & & & & -1 & & $\left(1-Y_{\mathrm{ac}}\right)$ & & & & $Y_{\mathrm{ac}}$ & & $\rho_{11}$ \\
\hline 12 & Penguraian hidrogen & & & & & -1 & $\left(1-Y_{\mathrm{h} 2}\right)$ & & & & & $\overline{Y_{\mathrm{h} 2}}$ & $\rho_{12}$ \\
\hline 13 & Pembusukan mikroba $X_{\text {su }}$ & & & & & & & -1 & & & & & $\rho_{13}$ \\
\hline 16 & Pembusukan mikroba $X_{\mathrm{c} 4}$ & & & & & & & & -1 & & & & $\rho_{16}$ \\
\hline 17 & Pembusukan mikroba $X_{\text {pro }}$ & & & & & & & & & -1 & & & $\rho_{17}$ \\
\hline 18 & Pembusukan mikroba $X_{\mathrm{ac}}$ & & & & & & & & & & -1 & & $\rho_{18}$ \\
\hline 19 & Pembusukan mikroba $X_{\mathrm{h} 2}$ & & & & & & & & & & & -1 & $\rho_{19}$ \\
\hline
\end{tabular}

mengacu pada nilai standar yang disarankan oleh ADM1 (Tabel II). Selanjutnya, suatu sistem persamaan diferensial dibangun untuk mengubah ekspresi persamaan laju menjadi model matematika yang dapat diselesaikan secara komputasi.

Pada penelitian ini, sistem persamaan diferensial tersebut diselesaikan dengan metode Hamming predictorcorrector. Pada prinsipnya, metode ini hampir sama dengan metode Adam-Bashford, hanya saja metode ini memiliki perbedaan pada perumusan predictor-corrector-nya. Metode Hamming predictor-corrector merupakan metode linear multi-langkah yang mendefinisikan nilai pada titik sebagai kombinasi linear dari titik-titik sebelumnya. [14]-[16] Untuk mengestimasi sebuah nilai $y_{k+1}=y\left(x_{k+1}\right)$, terdapat tiga langkah yang dilakukan pada metode ini, yaitu (i) menghitung nilai prediktor dengan menggunakan nilai sebelumnya, (ii) menghitung sebuah nilai modifier yang berfungsi untuk meningkatkan akurasi terhadap tebakan nilai awal, dan (iii) menghitung nilai korektor dengan menggunakan nilai yang sebelumnya telah dihitung. Ketiga langkah tersebut diulang hingga didapatkan suatu nilai yang lebih kecil dibandingkan dengan nilai error yang ditentukan. Penyelesaian model ADM1 dengan metode Hamming predictor-corrector diimplementasikan dengan menggunakan program Matlab. Dengan menyelesaikan model matematika tersebut, produksi biogas dapat disimulasikan pada periode waktu tertentu, serta profil konsentrasi masing-masing spesi selama simulasi dapat diaproksimasi. Akurasi dari simulasi dievaluasi dengan membandingkan konsentrasi metana hasil simulasi dengan data eksperimen. [17]

$$
\begin{aligned}
\rho_{5} & =k_{\mathrm{m}, \mathrm{su}} \frac{S_{\mathrm{su}}}{K_{\mathrm{S}, \mathrm{su}}+S_{\mathrm{su}}} X_{\mathrm{su}} \\
\rho_{9} & =k_{\mathrm{m}, \mathrm{c} 4} \frac{S_{\mathrm{bu}}}{K_{\mathrm{S}, \mathrm{bu}}+S_{\mathrm{bu}}} X_{\mathrm{c} 4} \\
\rho_{10} & =k_{\mathrm{m}, \mathrm{pro}} \frac{S_{\mathrm{pro}}}{K_{\mathrm{S}, \mathrm{pro}}+S_{\mathrm{pro}}} X_{\mathrm{pro}} \\
\rho_{11} & =k_{\mathrm{m}, \mathrm{ac}} \frac{S_{\mathrm{ac}}}{K_{\mathrm{S}, \mathrm{ac}}+S_{\mathrm{ac}}} X_{\mathrm{ac}} \\
\rho_{12} & =k_{\mathrm{m}, \mathrm{h} 2} \frac{S_{\mathrm{h} 2}}{K_{\mathrm{S}, \mathrm{h} 2}+S_{\mathrm{h} 2}} X_{\mathrm{h} 2} \\
\rho_{13} & =k_{\mathrm{dec} X_{\mathrm{su}}} X_{\mathrm{su}} \\
\rho_{16} & =k_{\mathrm{dec} X_{\mathrm{c} 4}} X_{\mathrm{c} 4} \\
\rho_{17} & =k_{\mathrm{dec} X_{\mathrm{pro}}} X_{\mathrm{pro}} \\
\rho_{18} & =k_{\mathrm{ac} X_{\mathrm{pro}}} X_{\mathrm{ac}} \\
\rho_{19} & =k_{\mathrm{h} 2 X_{\mathrm{pro}}} X_{\mathrm{h} 2} \\
\frac{d S}{d t} & =\Sigma_{j} \rho_{j} v_{i, j}
\end{aligned}
$$


Ali Assegaf. et.al.

Pemodelan Produksi Biogas...

TABLE II: Nilai standar dari parameter ADM1 [6]

\begin{tabular}{|c|c||c|c||c|c|}
\hline Parameter & Nilai & Parameter & Nilai & Parameter & Nilai \\
\hline$k_{\mathrm{m}, \mathrm{su}}$ & 1.250 & $K_{\mathrm{S}, \mathrm{su}}$ & 500 & $Y_{\mathrm{su}}$ & 0.10 \\
$k_{\mathrm{m}, \mathrm{c} 4}$ & 0.833 & $K_{\mathrm{S}, \mathrm{c} 4}$ & 200 & $Y_{\mathrm{c} 4}$ & 0.06 \\
$k_{\mathrm{m}, \mathrm{pro}}$ & 0.542 & $K_{\mathrm{S}, \mathrm{pro}}$ & 100 & $Y_{\mathrm{pro}}$ & 0.04 \\
$k_{\mathrm{m}, \mathrm{ac}}$ & 0.333 & $K_{\mathrm{S}, \mathrm{ac}}$ & 150 & $Y_{\mathrm{ac}}$ & 0.05 \\
$k_{\mathrm{m}, \mathrm{h} 2}$ & 1.458 & $K_{\mathrm{S}, \mathrm{ac}}$ & $7 \times 10^{-3}$ & $Y_{\mathrm{h} 2}$ & 0.06 \\
$f_{\mathrm{Y}, \mathrm{su}}$ & 0.10 & $f_{\mathrm{bu}, \mathrm{su}}$ & 0.13 & $k_{\mathrm{dec}}$ & 0.000833 \\
$f_{\mathrm{Y}, \mathrm{c} 4}$ & 0.06 & $f_{\mathrm{pro}, \mathrm{su}}$ & 0.27 & & \\
$f_{\mathrm{Y}, \mathrm{pro}}$ & 0.04 & $f_{\mathrm{ac}, \mathrm{su}}$ & 0.41 & & \\
$f_{\mathrm{Y}, \mathrm{cc}}$ & 0.05 & $f_{\mathrm{h} 2, \mathrm{su}}$ & 0.19 & & \\
$f_{\mathrm{Y}, \mathrm{h} 2}$ & 0.06 & & & & \\
\hline
\end{tabular}

\section{HASIL DAN DISKUSI}

Gambar 1 menunjukkan profil konsentrasi substrat yang terlibat dalam proses simulasi terhadap waktu. Pada awal simulasi, glukosa terurai dengan laju yang relatif cepat menjadi spesi asam propionat, asam butirat, hidrogen, dan asam asetat pada tahap asidogenesis. Pada saat yang bersamaan, konsentrasi asam propionat, asam butirat, hidrogen, asam asetat, dan metana mengalami kenaikan. Hasil simulasi menunjukkan bahwa konsentrasi seluruh substrat mengalami kenaikan hingga 20 jam simulasi. Asam propionat dan asam butirat mencapai konsentrasi maksimum masing-masing sebesar $38 \mathrm{mgCOD} / \mathrm{l}$ dan 21 $\mathrm{mgCOD} / \mathrm{lsetelah} 19 \mathrm{jam}$ simulasi. Setelah simulasi dilakukan selama $40 \mathrm{jam}$, konsentrasi asam propionat dan asam butirat habis terurai menjadi asam asetat, hidrogen, metana pada tahap asetogenensis. Selanjutnya, konsentrasi asam asetat mengalami penurunan secara perlahanan dan secara bersamaan konsentrasi metana mengalami kenaikan yang signifikan. Setelah 100 jam simulasi, konsentrasi asam asetat habis terurai seluruhnya menjadi metana. Pada titik ini, konsentrasi metana mencapai maksimum sebesar 417 $\mathrm{mgCOD} / \mathrm{l}$.

Gambar 2 menunjukkan pertumbuhan dari beberapa mikroorganisme pada proses pencernaan anaerobik, yaitu mikroorganisme yang mencerna glukosa, metana, asam propionat, asam asetat, dan hidrogen, dengan konsentrasi awal masing-masing sebesar $30 \mathrm{mgCOD} / \mathrm{l}$. Penentuan konsentrasi awal dari mikroorganisme tersebut berkaitan dengan proses optimasi yang akan dilakukan dan juga untuk menyederhanakan proses simulasi. Pada awal simulasi seluruh mikroorganisme mengalami pertumbuhan secara eksponensial dimana pertumbuhan mikroorganisme yang mencerna glukosa terjadi cukup signifikan yaitu $77 \mathrm{mgCOD} / 1$ setelah 31 jam simulasi. Hal ini disebabkan besarnya jumlah substrat glukosa yang terurai menjadi substrat lain, seperti asam propionat, asam butirat dan asam valerat. Selanjutnya, laju pertumbuhan mikroorganisme yang mencerna glukosa, asam propionat, asam butirat, dan hidrogen menurun setelah 45 jam simulasi. Hal tersebut terjadi karena laju pertumbuhan lebih kecil daripada laju kematian mikroorganisme. Akan tetapi, hasil simulasi menunjukkan bahwa mikroorganisme yang mencerna asam asetat mengalami kenaikan hingga konsentrasinya relatif konstan hingga akhir simulasi. Hal ini disebabkan laju pertumbuhan sama dengan laju kematian mikroorganisme tersebut.

Untuk menentukan akurasi perhitungan, konsentrasi metana yang diperoleh dari simulasi dibandingkan dengan data eksperimen. [17] Gambar 3 menunjukkan perbandingan konsentrasi metana yang didapat dari simulasi dan eksperimen. Setelah 20 jam simulasi, diketahui bahwa konsentrasi metana yang didapat dari simulasi lebih rendah (159,9 mgCOD/l) dibandingkan konsentrasi data eksperimen (170 mgCOD/l). Semakin lama simulasi dilakukan, perbedaan konsetrasi metana tersebut yang diketahui semakin besar. Misalnya setelah 106 jam simulasi, metana yang didapat dari simulasi adalah 417,48 mgCOD/1, sedangkan data eksperimen menunjukkan konsentrasi metana sebesar $330 \mathrm{mgCOD} / \mathrm{l}$. Salah satu penyebab masalah ini adalah nilai parameter yang digunakan hanya sesuai untuk periode simulasi tertentu. Untuk mengatasi masalah ini, proses optimasi parameter perlu dilakukan menggunakan suatu metode optimasi seperti algoritma genetika. [12]

Untuk mengetahui hubungan antara jumlah iterasi dan waktu yang dibutuhkan, proses simulasi dilakukan sebanyak 30 kali dengan memvariasikan nilai pembagi interval $(N)$. Jumlah iterasi didefinisikan dengan rumusan $10^{0.2 i}$, dengan nilai $i=0,1,2,3, \ldots, 30$. Gambar 4 menunjukkan perbandingan nilai $\log (N)$ terhadap waktu. Hasil simulasi menunjukkan bahwa peningkatan nilai $\log (N)$ akan berdampak 


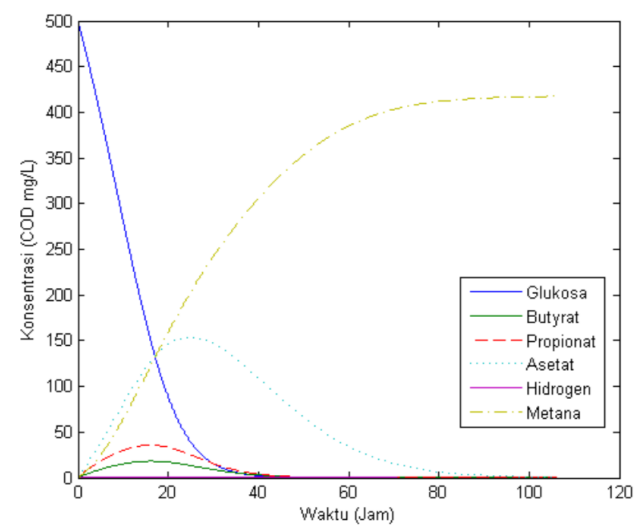

Fig. 1: Profil konsentrasi substrat utama selama periode simulasi.

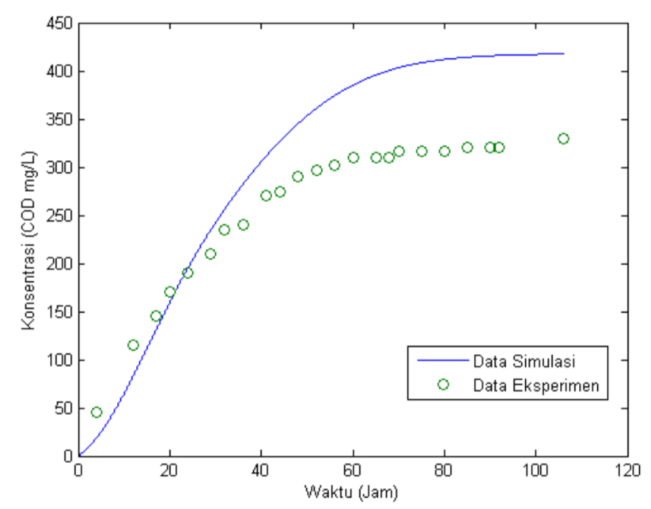

Fig. 3: Perbandingan simulasi vs eksperimen.

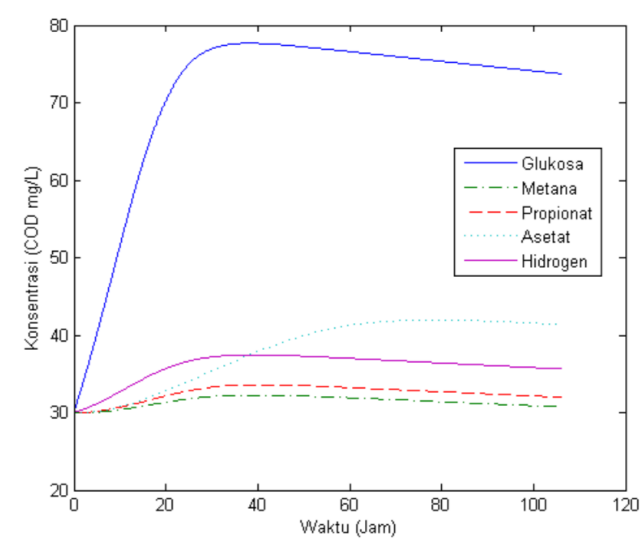

Fig. 2: Profil konsentrasi mikroorganisme selama periode simulasi.

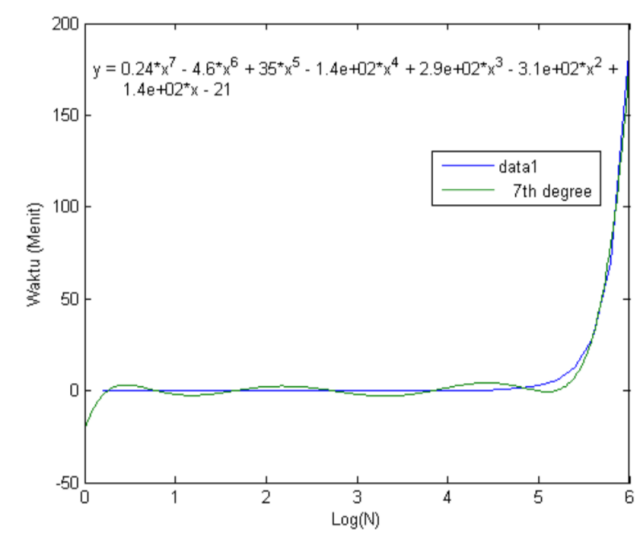

Fig. 4: Perbandingan jumlah iterasi vs waktu.

pada meningkatkannya waktu yang dibutuhkan untuk menyelesaikan simulasi. Hal tersebut berkaitan dengan semakin kecilnya jumlah langkah pada setiap iterasi.

Gambar 5 menunjukkan keterkaitan antara konsentrasi awal glukosa dan jumlah metana yang dihasilkan. Berdasarkan gambar tersebut dapat diketahui bahwa konsentrasi metana yang dihasilkan berbanding lurus dengan konsentrasi awal glukosa. Pada saat glukosa yang digunakan sebesar $100 \mathrm{mgCOD} / \mathrm{l}$, maka metana yang dihasilkan sebesar sekitar $83 \mathrm{mgCOD} / \mathrm{l}$. Selanjutnya penambahan jumlah metana yang dihasilkan relatif konstan sebesar 86 mgCOD/l. Gambar 6 menunjukkan bahwa konsentrasi awal glukosa berbanding lurus dengan iterasi minimum yang dibutuhkan untuk mendapatkan hasil yang diharapkan. Hal ini dikarenakan semakin besar konsentrasi awal glukosa akan menyebabkan semakin lamanya proses pencernaan anaerobik yang terjadi.

Gambar 7 menunjukkan bahwa konsentrasi mikroorganisme meningkat secara signifikan bersamaan dengan dihasilkannya metana. Selanjutnya, konsentrasi mikroorganisme tersebut relatif konstan pada saat konsentrasinya lebih dari $30 \mathrm{mgCOD} / \mathrm{L}$. Hal ini menunjukkan bahwa konsentrasi awal mikroorganisme tidak terlalu mempengaruhi konsentrasi metana yang dihasilkan. Gambar 8 menunjukkan penambahan konsentrasi mikroorganisme berbanding lurus terhadap jumlah iterasi minimum untuk mendapatkan grafik yang diharapkan. Hal tersebut dikarenakan semakin besar konsentrasi mikroorganisme yang digunakan menyebabkan semakin lamanya proses pencernaan anaerobik yang terjadi. 
Ali Assegaf. et.al.

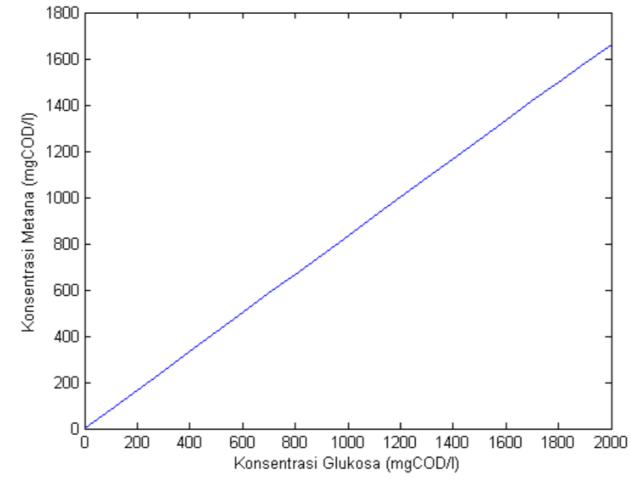

Fig. 5: Perbandingan jumlah glukosa vs metana.

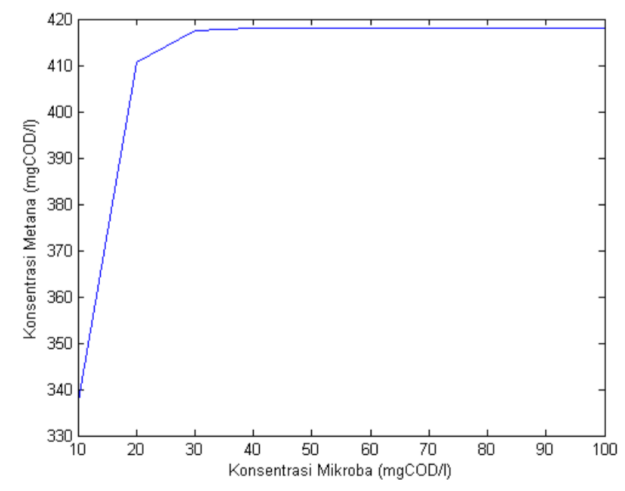

Fig. 7: Konsentrasi mikroorganisme vs metana.

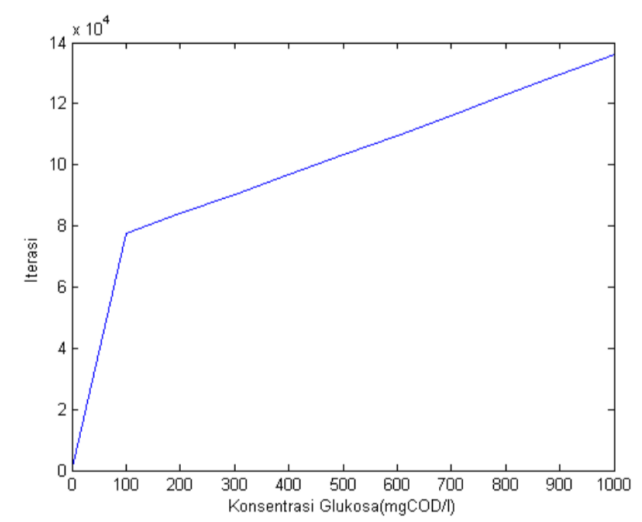

Fig. 6: Konsentrasi awal glukosa vs iterasi minimum.

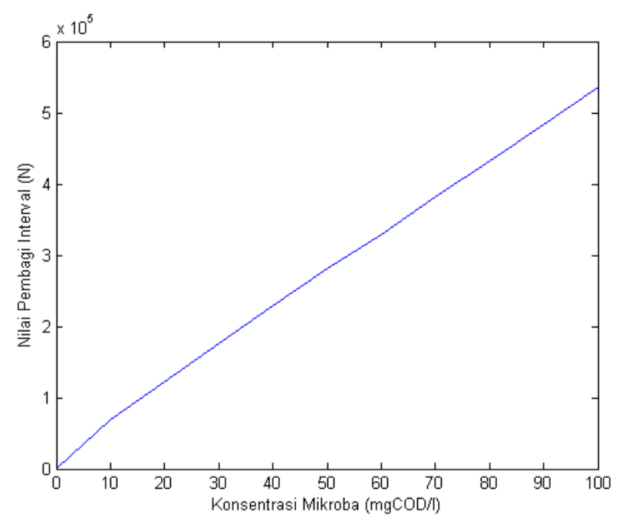

Fig. 8: Konsentrasi mikroorganisme vs iterasi minimum.

\section{KESIMPULAN}

Proses simulasi pencernaan anaerobik dengan menggunakan metode Hamming predictor-corrector menghasilkan konsentrasi metana yang cukup akurat dibandingkan data eksperimen pada periode simulasi 30 jam pertama. Akan tetapi, setelah melewati 30 jam simulasi, akurasi konsentrasi metana yang dihasilkan dari simulasi kurang baik. Dari simulasi, dapat diketahui profil kinetika reaksi dari spesi yang terlibat dalam simulasi, di antaranya glukosa, asam propionat, asam butirat, asam asetat, hidrogen, dan metana. Hasil simulasi juga menunjukkan bahwa semakin besar konsentrasi awal substrat dan mikroorganisme mengakibatkan meningkatnya jumlah iterasi yang dibutuhkan.

\section{REFERENCES}

[1] Mark Z. Jacobson and Mark A. Delucchi. (March, 2011). Providing all global energy with wind, water, and solar power, Part I: Technologies, energy resources, quantities and areas of infrastructure, and materials. Energy Policy, 39(3):1154-1169.

[2] Jeffrey Chow, Raymond J. Kopp, and Paul R. Portney. (November, 2003). Energy Resources and Global Development. Science, 302(5650):1528-1531.

[3] Paul R. Ehrlich and John P. Holdren. (1971). Impact of Population Growth. Science, 171(3977):1212-1217.

[4] A. E. Atabani, A. S. Silitonga, Irfan Anjum Badruddin, T. M. I. Mahlia, H. H. Masjuki, and S. Mekhilef. (May, 2012). A comprehensive review on biodiesel as an alternative energy resource and its characteristics. Renewable and Sustainable Energy Reviews, 16(4):2070-2093.

[5] L. C. Martins das Neves, A. Converti, and T. C. Vessoni Penna. (August, 2009). Biogas Production: New Trends for Alternative Energy Sources in Rural and Urban Zones. Chemical Engineering \& Technology, 32(8):1147-1153. 
[6] D. J. Batstone, J. Keller, I. Angelidaki, S. V. Kalyuzhnyi, S. G. Pavlostathis, A. Rozzi, W. T. M. Sanders, H. Siegrist, and V. A. Vavilin. (2002). The IWA Anaerobic Digestion Model No 1 (ADM1). Water Science and Technology: A Journal of the International Association on Water Pollution Research, 45(10):65-73.

[7] D. J. Batstone, J. Keller, and J. P. Steyer. (August, 2006). A review of ADM1 extensions, applications, and analysis: 2002-2005. Water Science and Technology, 54(4):1-10.

[8] J. Ziegenhirt, T. Bartz-Beielstein, O. Flasch, W. Konen, and M. Zaefferer. Optimization of biogas production with computational intelligence a comparative study. In IEEE Congress on Evolutionary Computation, pages 1-8, (July, 2010).

[9] I. Angelidaki and B. K. Ahring. (February, 2000). Methods for increasing the biogas potential from the recalcitrant organic matter contained in manure. Water Sci Technol, 41(3):189-194.

[10] Lise Appels, Jan Baeyens, Jan Degrãílve, and Raf Dewil. (December, 2008). Principles and potential of the anaerobic digestion of waste-activated sludge. Progress in Energy and Combustion Science, 34(6):755-781.

[11] Muhammad Romli. Modelling and verification of a two-stage high-rate anaerobic wastewater treatment system. $\mathrm{PhD}$ thesis, University of Queensland, (1993).

[12] Isman Kurniawan and Annisa Aditsania. (March, 2016). Pemodelan Dan Simulasi Produksi Biogas Dari Substrat Glukosa Menggunakan Anaerobic Digestion Model No. 1 (ADM1). Indonesian Journal on Computing (Indo-JC), 1(1):49-60.

[13] Ardhyka Dewantara, Rian Febrian Umbara, and Isman Kurniawan. (September, 2017). Implementasi Metode Runge-Kutta-Gill pada Anaerobic Digestion Model No. 1 untuk Memodelkan Produksi Biogas. Indonesian Journal on Computing (Indo-JC), 2(1):1-6.

[14] Robert R. Brown, James D. Riley, and Morris M. Bennett. (1965). Stability Properties of Adams-Moulton Type Methods. Mathematics of Computation, 19(89):90-96.

[15] P. E. Chase. (October, 1962). Stability Properties of Predictor-Corrector Methods for Ordinary Differential Equations. J. ACM, 9(4):457-468.

[16] R. L. Crane and R. W. Klopfenstein. (April, 1965). A Predictor-Corrector Algorithm with an Increased Range of Absolute Stability. J. ACM, 12(2):227-241.

[17] Hyeong-Seok Jeong, Chang-Won Suh, Jae-Lim Lim, Sang-Hyung Lee, and Hang-Sik Shin. (April, 2005). Analysis and application of ADM1 for anaerobic methane production. Bioprocess and Biosystems Engineering, 27(2):81-89. 
